\title{
Cardiorenal Fat: A Cardiovascular Risk Factor With Implications in Chronic Kidney Disease
}

\begin{abstract}
Luis D'Marco $^{1 *}$, María Jesús Puchades ${ }^{1,2}$, Nayara Panizo ${ }^{1}$, María Romero-Parra ${ }^{1}$, Lorena Gandía ${ }^{1}$, Elena Giménez-Civera ${ }^{1}$, Elisa Pérez-Bernat ${ }^{1}$, Miguel Gonzalez-Rico ${ }^{1}$ and José Luis Gorriz ${ }^{1,2}$
\end{abstract}

${ }^{1}$ Nephrology Department, Hospital Clínico Universitario, Institute of Health Research (INCLIVA), Valencia, Spain, ${ }^{2}$ Universidad de Valencia, Medicine School, Valencia, Spain

There is a growing interest in the potential role of adipose tissues in cardiac and renal pathophysiology, and determining the mechanisms by which fat compartments around the heart and kidneys influence cardiovascular disease is of clinical importance in both general and high-risk populations. Epicardial fat and perirenal fat have been associated with adverse outcomes in chronic kidney disease (CKD) patients. Epicardial fat is a rich source of free fatty acids and is capable of secreting inflammatory and pro-atherogenic cytokines that promote atherosclerosis through a local paracrine effect. Recent evidence has demonstrated that perirenal fat has a closer correlation with kidney diseases than other visceral fat deposits in obesity or metabolic disturbances. Moreover, perirenal fat has been reported as an independent risk factor for CKD progression and even associated with cardiorenal dysfunction. Accordingly, these forms of organ-specific fat deposits may act as a connecter between vascular and cardiorenal disease. This review explores the possible links between epicardial and perirenal fat and its significant role as a modulator of cardiorenal dysfunction in CKD patients.

Keywords: chronic kidney disease, adipose tissue, cardiovascular disease, cardiorenal disease, renal failure

\section{INTRODUCTION}

Interest in the potential impact of organ-specific adipose tissue on cardiac and renal pathophysiology is growing, and it is clinically important to determine the mechanisms by which fat compartments around the heart and kidneys influence cardiovascular disease (CVD) in both general and high-risk populations $(1,2)$. In these sense, epicardial fat $(\mathrm{EF})$ and perirenal fat $(\mathrm{PF})$ have been associated with adverse outcomes in chronic kidney disease (CKD) patients (3-5). EF and $\mathrm{PF}$ tissues accumulate with overweight and obesity (6), which are associated with microalbuminuria $(7,8)$, and thus with worse prognosis in CVD patients (9).

The close anatomical proximity and intercommunication between EF, coronary arteries and myocardium has been reported as a key factor in atherosclerotic disease development and progression (10). As a rich source of free fatty acids capable of secreting inflammatory and proatherogenic cytokines, $\mathrm{EF}$ is believed to promote atherosclerosis of the intra-epicardial branches of coronary arteries through a local paracrine effect. Interestingly, local secretion of certain adipocytokines in inflamed peri-coronary adipose tissue may have adverse consequences on myocardial contractility and vascular calcification (11). PF, the adipose tissue surrounding the kidneys, was originally thought to provide only mechanical kidney support, yet studies have shown have a closer association of PF with kidney diseases than other visceral fat deposits in obesity 
or metabolic disturbances (12). PF has recently been identified as an independent risk factor for CKD progression and is even associated with cardiorenal dysfunction (13). Finally, these forms of organ-specific fat deposit may act as a connector between vascular and cardiorenal disease. This review outlines the evidence of possible links between epicardial and PF and its significant role as a modulator of cardiorenal dysfunction under pathologic conditions in patients affected by renal disease.

\section{EPICARDIAL FAT}

EF represents adipose tissue located below the visceral pericardium in direct contact with the epicardial coronary arteries (14). EF originates in the splanchnopleuric mesoderm, without fascia separating it from myocardium and arteries, which allows a direct flow of fatty substances to the coronary arteries and myocardium (15). Moreover, EF can also be found amid myocardial fibers, generally next to the intra-myocardial branches of the coronary arteries $(16,17)$.

Although the functional role of EF is complex and currently remains undefined, this tissue participates in multiple areas, such as mechanical, metabolic, thermogenic and endocrine/paracrine/autocrine functions (18). EF accompanies the principal branches of the coronary arteries along their atrioventricular course to provide mechanical protection against excessive deformation during the cardiac cycle (19). Moreover, EF is actively involved in energy production and lipid homeostasis, and has a higher rate of free fatty acid (FFA) release and absorption than other fat deposits (18). Since myocardial metabolism is dependent on FFA oxidation, EF supports myocardial energy needs, especially during periods of high demand (19). Like PF, brown adipose tissue is rich in mitochondria with significant production of the uncoupling protein-1 (UCP1) needed to produce heat in response to cold exposure. Evidence has shown that expression of UCP1 and related genes is higher in EF and other fat deposits such as abdominal or subcutaneous adipose tissue (20). These findings indicate a role for $\mathrm{EF}$ in heat production to protect the heart from hypothermia.

Studies in animals and humans have shown that EF secrete an abundance of cytokines (Table 1), which are implicated in control of endothelial function, coagulation, and inflammation $(11,16)$. These numerous bioactive molecules produced by EF can protect or negatively affect the myocardium and coronary arteries (21). Under physiological conditions, EF secretes cytokines with anti-inflammatory and antiatherosclerotic properties, such as adiponectin and leptin (22). Secreted by adipocytes, adiponectin has antioxidant, anti-inflammatory and anti-atherogenic actions (23): it stimulates the oxidation of fatty acids via a protein kinase pathway to reduce lipid storage in the myocardium, and also inhibits production of inflammatory mediators to maintain an anti-inflammatory environment in the cardiovascular system. Conversely, under pathological conditions adiponectin production by EF drops, while production and secretion of pro-inflammatory or pro-atherogenic cytokines (such as leptin, vinfatin, or apelin) are increased (11, 21). Studies have linked leptin with pro-atherogenic effects, hypertension, endothelial dysfunction, inflammation, oxidative stress, and proliferation of vascular smooth muscle cells $(24,25)$, yet surprisingly, adipocyte-derived factors such as adiponectin and leptin remain controversial in the setting of renal dysfunction.

\section{PERIRENAL FAT}

PF represents fat located in the retroperitoneal space surrounding the kidneys. Renal sinus fat is also a component of PF and this adipose tissue is surrounded by fascia tissue. Regardless of its preadipocyte origin, PF undergoes an unusual progressive transition from brown to white adipose tissue after birth (26). In adults, $\mathrm{PF}$ is composed of a combination of white and brown adipose tissue (27). Anatomically, this fat is extensively vascularized by abdominal aorta branches including the inferior adrenal, dorsal, and gonadal arteries (28).

TABLE 1 | Pathophysiological effects of adipocytokines produced in organ-specific adipose tissue.

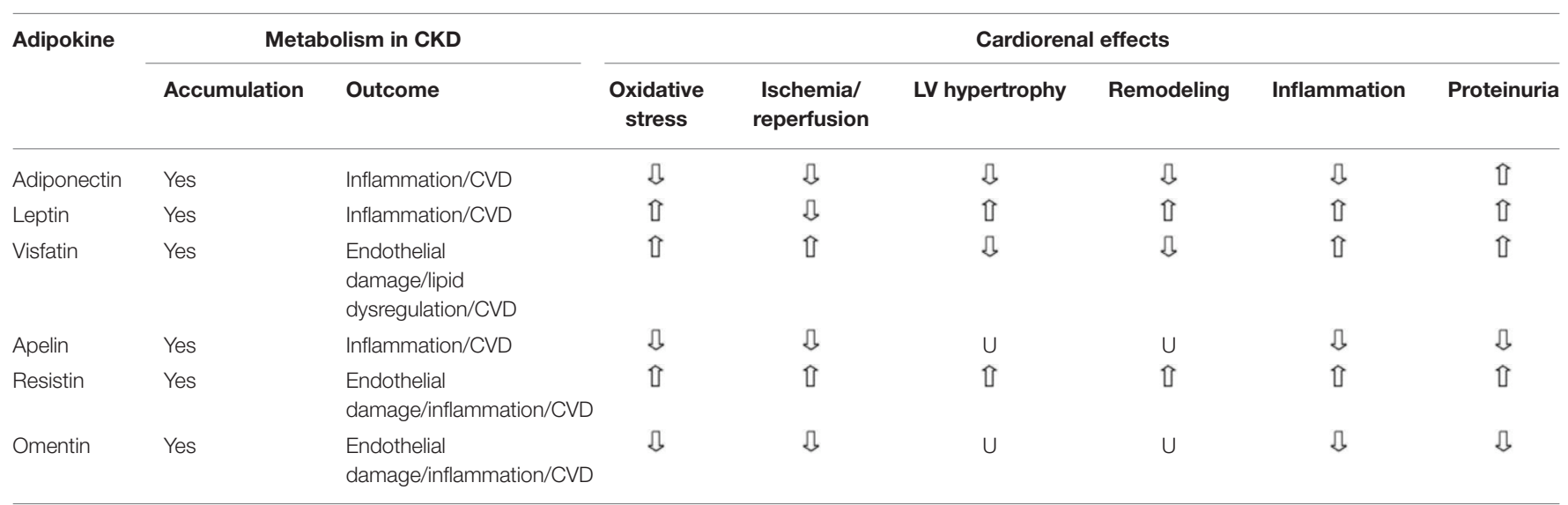

CKD, chronic kidney disease; CVD, cardiovascular disease; LV, left ventricle; U, unknown. Adapted from D'Marco et al. (11). 


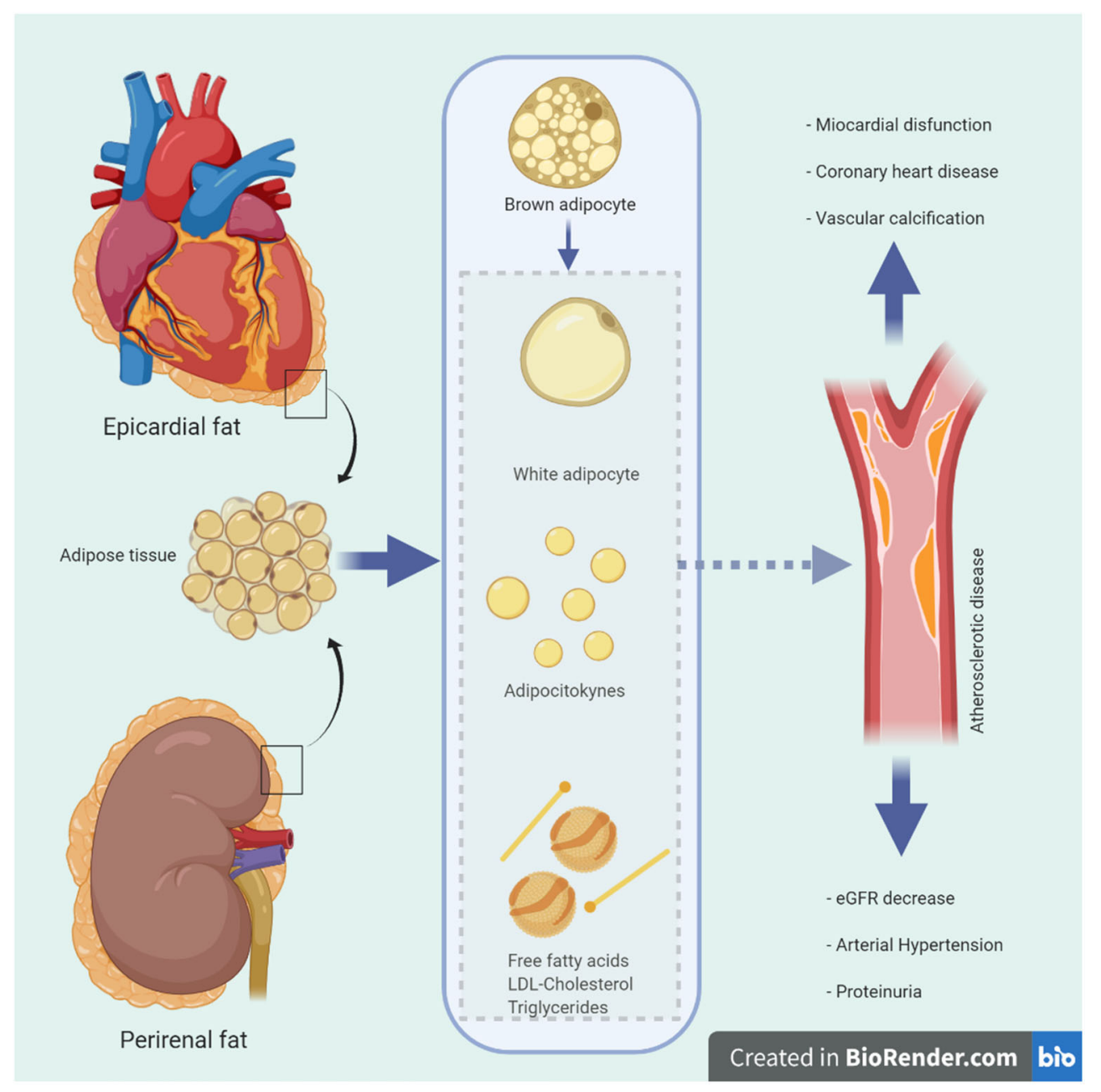

FIGURE 1 | Possible physiological and pathological mechanisms of epicardial and renal fat in vascular beds. Schematic diagram illustrating the anatomical location of epicardial and perirenal fat around the heart and kidneys, its various pathophysiological functions and proposed pathways of damage with adverse clinical consequences. eGFR, estimated glomerular filtration rate; LDL, low density lipoprotein.

Research has focused on the connections between the kidneys and PF, as well as between this tissue and bodily function. As observed in EF, PF produces and secretes adipokines and pro-inflammatory cytokines, including adiponectin, leptin, visfatin, resistin, tumor necrosis factor- $\alpha$ and interleukin6 (IL-6), among others $(13,29)$ (Table 1). Moreover, these substances pass near to the kidneys and assist in regulating renal function through endocrine and paracrine pathways (30). PF has therefore been linked to direct lipotoxic effects such as increasing hydrostatic pressure in the glomerulus, activating the renin-angiotensin-aldosterone system, and accelerating CKD progression $(31,32)$. In this regard, an association between $\mathrm{PF}$ and abdominal obesity and albuminuria has been detected in obese patients $(33,34)$. Although studies have reported an association of PF with CKD progression, new evidence on the presence and accumulation of $\mathrm{PF}$ is warranted in this risk group $(35,36)$.

\section{ORGAN-SPECIFIC FAT MEASUREMENT TECHNIQUES}

Several non-invasive techniques have been used to measure body fat distribution, especially via computed tomography (CT) and magnetic resonance imaging (MRI) $(37,38)$, although their use is hindered by the high cost and exposure to radiation. Studies have demonstrated that ultrasound is a practical and reasonable alternative to CT or MRI, given that this imaging technique involves no radiation exposure and is cheap and reproducible (39). Other studies have explored the use of abdominal ultrasound to determine PF burden (40). EF has also been measured with echocardiography techniques; however, these imaging methods offer only a partial approach to organspecific adipose tissue, since measurement is limited to tissue (41). In contrast, CT and MRI techniques allow more spatial resolution with extended measures such as the total volume 
TABLE 2 | Different studies showing epicardial and perirenal fat with different outcomes in CKD populations.

\begin{tabular}{|c|c|c|c|c|}
\hline References & Technique & Study population & $N$ & Outcomes \\
\hline \multicolumn{5}{|l|}{ Perirenal Fat } \\
\hline Shen et al. (34) & Ultrasound & T2DM patients with Albuminuria & 89 & $\begin{array}{l}\text { Increased PF was associated with albuminuria in patients with } \\
\text { T2DM }\end{array}$ \\
\hline D’Marco et al. (5) & Ultrasound & CKD patients in all stages (non-dialysis) & 103 & $\begin{array}{l}\text { PF thickness was associated with metabolic risk factors in } \\
\text { CKD patients }\end{array}$ \\
\hline Fang et al. (35) & Ultrasound & Patients with T2DM and reduced eGFR & 171 & $\begin{array}{l}\text { This study confirmed a negative independent relationship } \\
\text { between PF and eGFR in patients with T2DM }\end{array}$ \\
\hline Geraci et al. (36) & Ultrasound & Hypertensive patients & 216 & $\begin{array}{l}\text { PF significantly correlated with eGFR with no differences in } \\
\text { groups divided by sex, diabetes, or BMI. }\end{array}$ \\
\hline Lamacchia et al. (44) & Ultrasound & T2DM subjects & 151 & $\begin{array}{l}\text { PF was an independent predictor of eGFR decrease and } \\
\text { altered renal resistance index and hyperuricemia }\end{array}$ \\
\hline Koo et al. (45) & $\mathrm{CT}$ & $\begin{array}{l}\text { Asymptomatic subjects, hypertension and } \\
\text { dyslipidemia. }\end{array}$ & 3.919 & PF was independently associated with vascular calcifications. \\
\hline \multicolumn{5}{|l|}{ Epicardial fat } \\
\hline Turkmen et al. (43) & CT & $\begin{array}{l}\text { ESKD patients on dialysis }+27 \text { healthy } \\
\text { subjects. }\end{array}$ & 80 & $\begin{array}{l}\text { EF significantly correlated with MIA syndrome in ESKD } \\
\text { patients }\end{array}$ \\
\hline Karohl et al. (3) & CT & $\begin{array}{l}\text { CKD stages } 4-5 \text { patients awaiting kidney } \\
\text { transplantation }\end{array}$ & 411 & $\begin{array}{l}\text { EF was the best predictor of abnormal myocardial perfusion } \\
\text { in CKD patients. }\end{array}$ \\
\hline D'Marco et al. (4) & CT & HD patients & 95 & $\begin{array}{l}\text { Each } 10 \mathrm{cc} \text { increase in EF volume was associated with a } \\
\text { significant } 6 \% \text { increase in risk of death during follow-up }\end{array}$ \\
\hline Erdur et al. (42) & CT & $\begin{array}{l}\text { ESRD patients on dialysis }+42 \text { healthy } \\
\text { subjects }\end{array}$ & 76 & Age and $\mathrm{BMI}$ are independent predictors of EF. \\
\hline Ko et al. (46) & CT & HD patients & 109 & $\begin{array}{l}\text { EF progression slows significantly with non-calcium-based } \\
\text { resins (Sevelamer) }\end{array}$ \\
\hline Karatas et al. (47) & Echocardiography & CKD and HD patients + healthy subjects & 111 & $\begin{array}{l}\text { EF is significantly high in HD patients compared to pre-HD } \\
\text { and healthy subjects. }\end{array}$ \\
\hline Ayan et al. (48) & Echocardiography & CKD all stages, dialysis, and healthy subjects & 97 & $\begin{array}{l}\text { No correlations between EF thickness and inflammatory } \\
\text { markers were found. }\end{array}$ \\
\hline Cano Megías et al. (49) & CT & CKD and HD patients & 104 & $\begin{array}{l}\text { A higher EF was associated with increased mortality and } \\
\text { lower free survival time to fatal and non-fatal cardiovascular } \\
\text { events }\end{array}$ \\
\hline
\end{tabular}

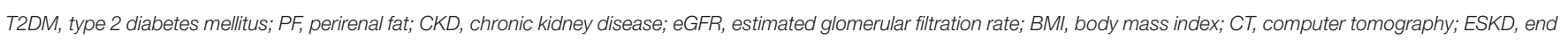
stage kidney disease; EF, epicardial fat; MIA, malnutrition inflammation atherosclerosis; HD, hemodialysis.

of fat surrounding these organs. Finally, although DEXA and Bioimpedance techniques offer interesting quantification of total body fat, as yet no specific organ compartments can be measured by these devices.

\section{ORGAN-SPECIFIC FAT AS CAUSATIVE FACTOR OF CARDIORENAL DISEASE}

Recent evidence has shown that region-specific adipose tissue is an important cardiovascular risk marker in the general and high-risk population. For example, there appears to be a connection between EF and CVD in conditions as common as high blood pressure, metabolic syndrome, diabetes, and cardiorenal disease $(31,32)$. Recognition of the adipocyte as a cell type with complex functioning including endocrine, paracrine and autocrine capacity has aroused research interest in disciplines such as nephrology, cardiology, and endocrinology, and it has become a fertile ground for scientific debate. Its wide heterogeneity of location, functions, proteomics, and metabolomics (1) are particularly important in adiposity, where changes in function and volume are associated with increased cardiorenal and metabolic risk (Figure 1).

Although studies evaluating EF in CKD are still ongoing, some research has reported a relationship between EF and vascular disease in patients with renal involvement $(42,43)$ (Table 2). In a study carried out in a cohort of more than 400 patients with CKD stage 4-5 and 5 on dialysis EF emerged as a risk factor for alterations in myocardial perfusion as well as appearance of vascular calcification (3), and was also independently associated with vascular calcification in predicting myocardial perfusion defects in this study. Karatas et al. recently demonstrated that EAT thickness measured by echocardiography was significantly greater in hemodialysis patients than in those in pre-dialysis stages or in healthy subjects (47). Similarly, in a sub analysis of the RIND study (Renagel in a new dialysis trial), which initially evaluated the presence of coronary artery calcifications (CAC) and alterations in calcium and phosphorus in patients starting dialysis treatment, it was observed that each $10 \mathrm{cc}$ increase in EF volume raised mortality by $6 \%$ (4). Other factors such as CAC and age were also associated with increased mortality. Further publications have reported that patients with CKD have higher EF thickness and volume compared to control subjects (50). 


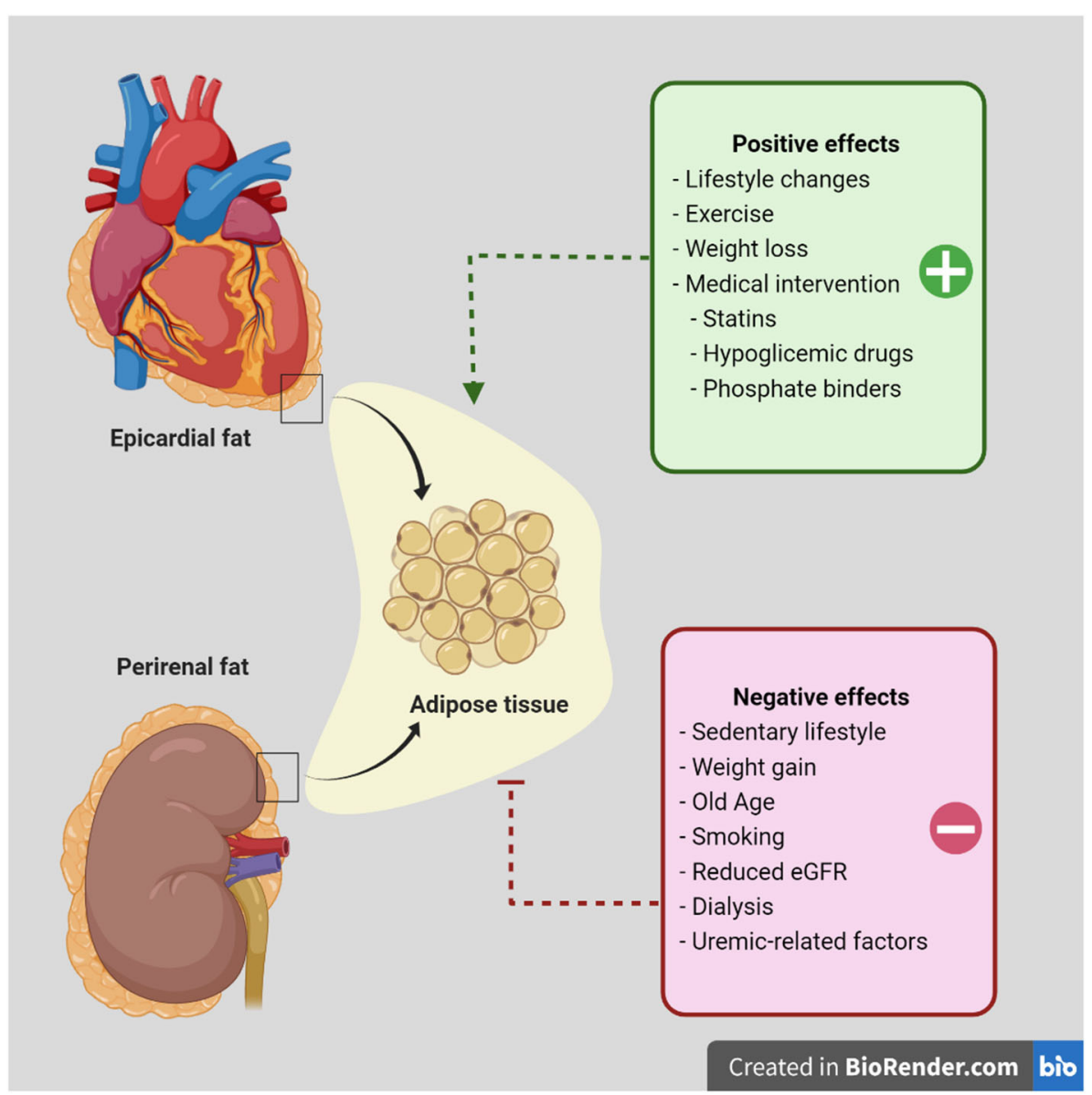

FIGURE 2 | Proposed factors that improve or worsen epicardial or perirenal fat tissue accumulation in patients with chronic kidney disease. Diagram showing adipose tissue around the heart and kidney. In a pathological environment, this adipose tissue becomes a cardiovascular risk factor in susceptible populations. Current evidence has been published regarding the effect of lifestyle changes and weight loss or exercise. Moreover, medical intervention has supported the use of hypoglycemic agents and other drugs to reduce adipose tissue accumulation and/or dysfunction. Although further evidence regarding perirenal fat intervention is warranted in future studies, controlling metabolic abnormalities such as hyperglycemia, dyslipidemia or hyperuricemia may improve clinical outcomes.

Conversely, in other research EF was not confirmed as an isolated risk predictor but rather as a cofactor associated with body mass index (BMI) and other obesity indices.

Recent studies have identified excess PF as an emerging risk marker of CVD, independently of common metabolic risk factors $(13,44)$. Our previous analysis showed that PF thickness was associated with metabolic risk factors in non-dialysis-dependent patients (5). Other investigations found PF thickness to be positively correlated with high blood pressure in overweight patients and hypertension $(6,51)$. Moreover, higher levels of PF have been linked with carotid intima-media thickness, indicating that excess PF is associated with atherosclerosis and CVD (52).

As a CVD-related risk factor, diabetes or dyslipidemiaassociated PF may also indirectly contribute to CVD. A recent study showed that excess PF was independently associated with hyperinsulinemia and insulin resistance in obese patients, irrespective of other anthropometric or metabolic parameters, suggesting $\mathrm{PF}$ as a strong marker of insulin resistance (6). Moreover, PF development and remodeling have also been associated with other metabolic parameters in patients with CKD.
Hence, PF thickness was significantly correlated with abnormal triglycerides and uric acid levels, in which patients with stage 4 and $5 \mathrm{CKD}$ had the greatest PF thickness (5). Of interest, excess $\mathrm{PF}$ is associated with a reduced glomerular filtration rate, regardless of other indices of adiposity, in patients with hypertension and or diabetes (36). A more recent study reported a positive correlation between PF and albuminuria among type 2 diabetes patients (35).

The physio-pathological processes and association of these specific cardiac and renal adipose tissues allow the hypothesis that an excess of epicardial and PF contributes to CVD. PF is potentially related to $\mathrm{EF}$ as both exhibit mesothelial layers like visceral organs enriched in white adipose tissue progenitors which produce adipocytes $(12,53)$. This finding bolsters the hypothesis of $\mathrm{PF}$ as a risk predictor for CVD in the renalaffected population, and likewise, EF has been considered a CVD risk factor that predicts cardiac dysfunction in CKD patients $(48,49)$. Regarding this latter proposal, these adipose tissues are linked to proven cardiovascular indicators such as carotid intimamedia thickness and vascular calcifications indexes $(4,45,52)$, 
and they also express browning fat markers with interactions between both tissues through complex endocrine pathways with differential behaviors to those observed in other adipose tissues (54-56).

\section{ADIPOSE TISSUE AND BONE MINERAL AXIS WITH CARDIORENAL IMPLICATIONS}

Elevated serum levels of fibroblast grow factor 23 (FGF23) are strongly associated with increased CVD in CKD patients. Hence, FGF23 levels rise as kidney function declines, with the result that in patients with end state kidney disease (ESKD), FGF23 contributes to hypertension, vascular calcification, and left ventricular hypertrophy by distinct mechanisms (57). It is currently accepted that adipocytes are capable of storing vitamin $\mathrm{D}$, and beyond this activity new evidence has revealed crosstalk between energy storage organs such as adipose tissues and bone. Recent reports show that adiponectin and leptin directly stimulate FGF23 expression in the skeleton (58), thus suggesting a link between these adipokines and FGF23. Moreover, a recent investigation found adiponectin to be a strong modulator of FGF23 response to vitamin D receptor (VDR) activation in CKD patients (59). Of note, mice overexpressing the most abundant adipose tissue protein, adiponectin, exhibit a substantially enhanced FGF23 response to phosphate load compared with wild-type and adiponectin knock-out mice. Additionally, VDR activation markedly upregulates FGF23 gene expression and substantially increases circulating levels of FGF23 in healthy subjects with vitamin D deficiency and CKD patients. Accordingly, the association between FGF23 and fat mass was correlated with higher serum leptin levels in animal models, which adds support for leptin regulation of FGF23, and thus FGF23 was also associated with cardiac and endothelial damage (60). Beyond the correlation between EF and coronary calcification, insulin resistance and inflammation (IL-6), FGF23 has showed an association with EF in stage 3-5 CKD patients (61).

We postulated that local peri-vascular expression of adiponectin and leptin may dysregulate local FGF-23 production in calcified endothelial cells, suggesting the possibility of an undercover regulatory pathway in a uremic environment. This mechanism may explain why EF has been reported as an independent risk factor for CAC and myocardial dysfunction in CKD patients (3).

\section{THERAPEUTIC APPROACHES}

Organ-specific adipose tissue reduction has been achieved with lifestyle changes and pharmacological interventions

\section{REFERENCES}

1. D’Marco L, Cortez M, Salazar M, Lima-Martínez M, Bermúdez V. Epicardial adipose tissue: a cardiovascular risk marker to evaluate in chronic kidney disease. Clin Invest Arterioscler. (2020) 32:129-34. doi: 10.1016/j.artere.2020.05.004

2. Russo R, di Iorio B, di Lullo L, Russo D. Epicardial adipose tissue: new parameter for cardiovascular risk assessment in high risk
(Figure 2). Intriguingly, a study showed a $2 \%$ regression in $\mathrm{EF}$ volume in patients who lost $5 \%$ of their body weight, compared to a $23 \%$ increase in those who gained weight (62). Moreover, other reports describe decreased EF volume after intensive lipid-lowering therapy with statins $(63,64)$. This effect may be related to the known anti-inflammatory activity and inhibition of vasa-vasorum proliferation shown by statins (65).

In a recent study, Couselo-Seijas et al. showed that treatment with sodium-glucose co-transporter 2 inhibitor (SGLT2i) reduced EF (66), and use of an SGLT2i (Dapagliflozin) thus improved glucose metabolism with no lipogenesis-involved gene regulation or lactate production, mainly in patients with CAC. Interesting findings from another study provide insights into the distinctive role of the PPAR $\alpha$ /adiponectin/SGLT2 pathways in regulating sodium and glucose homeostasis in PF (67). This work showed that excessive sodium intake also increased plasma level of adiponectin, as well as its expression in both PF and renal cortex. Other research indicated that glucagonlike peptide-1 (GLP-1) analogs Exenatide and Liraglutide are effective in reducing EF in obese patients with diabetes mellitus, effects that are mostly weight-loss dependent (68). In diabetic patients, adding a dipeptidyl peptidase-4 (DPP-4) inhibitor to standard care therapies produced a significant decrease in EF volume over 2-year follow-up (41). Similar benefits have been observed with pioglitazone in patients with metabolic syndrome (69).

In patients with ESKD, use of non-calcium-based phosphate binding agent sevelamer reduced serum cholesterol and markers of inflammation (70). Additionally, sevelamer has shown to be effective in slowing down CAC progression and EF in dialysis patients (46). The effect of weight loss and regular exercise on accumulation of visceral adipose tissue in CKD patients remains to be elucidated.

\section{CONCLUSIONS}

Renal-affected patients express extremely high incidence of CVD usually attributed to classical and uremic-related conditions. This suggests that specific adipose tissues may represent an additional cardiovascular risk factor in CKD patients. Finally, organ-specific adipose tissue, specifically EF and PF, represents an interesting and underexplored field to consider in this population.

\section{AUTHOR CONTRIBUTIONS}

All authors listed have made a substantial, direct and intellectual contribution to the work, and approved it for publication.

populations. J Nephrol. (2018) 31:847-53. doi: 10.1007/s40620-0180491-5

3. Karohl C, D’Marco L, Bellasi A, Raggi P. Hybrid myocardial imaging for risk stratification prior to kidney transplantation: added value of coronary calcium and epicardial adipose tissue. J Nucl Cardiol. (2013) 20:1013-20. doi: 10.1007/s12350-013-9761-8

4. D'Marco LG, Bellasi A, Kim S, Chen Z, Block GA, Raggi P. Epicardial adipose tissue predicts mortality in incident hemodialysis patients: a substudy of the 
Renagel in new dialysis trial. Nephrol Dial Transplant. (2013) 28:2586-95. doi: 10.1093/ndt/gft264

5. D’Marco L, Salazar J, Cortez M, Salazar M, Wettel M, Lima-Martínez M, et al. Perirenal fat thickness is associated with metabolic risk factors in patients with chronic kidney disease. Kidney Res Clin Pract. (2019) 38:365-72. doi: 10.23876/j.krcp.18.0155

6. Manno C, Campobasso N, Nardecchia A, Triggiani V, Zupo R, Gesualdo L, et al. Relationship of para- and perirenal fat and epicardial fat with metabolic parameters in overweight and obese subjects. Eat Weight Disord. (2019) 24:67-72. doi: 10.1007/s40519-018-0532-z

7. Turan Y, Turan E. Aortic stiffness index and carotid intima-media thickness are independently associated with the presence of microalbuminuria in patients with type 2 diabetes mellitus. Diabetes Metab Syndr Obes Targets Ther. (2019) 12:1889-96. doi: 10.2147/DMSO.S223880

8. Hou N, Han F, Wang M, Huang N, Zhao J, Liu X, et al. Perirenal fat associated with microalbuminuria in obese rats. Int Urol Nephrol. (2014) 46:839-45. doi: 10.1007/s11255-014-0656-7

9. Byambasukh O, Eisenga MF, Gansevoort RT, Bakker SJ, Corpeleijn E. Body fat estimates from bioelectrical impedance equations in cardiovascular risk assessment: the PREVEND cohort study. Eur J Prev Cardiol. (2019) 26:905-16. doi: $10.1177 / 2047487319833283$

10. Bornachea O, Vea A, Llorente-Cortes V. Interplay between epicardial adipose tissue, metabolic and cardiovascular diseases. Clin Investig Arterioscler. (2018) 30:230-9. doi: 10.1016/j.arteri.2018.03.003

11. D'Marco L, Puchades MJ, Gorriz JL, Romero-Parra M, Lima-Martínez M, Soto C, et al. Epicardial adipose tissue, adiponectin and leptin: a potential source of cardiovascular risk in chronic kidney disease. Int J Mol Sci. (2020) 21:978. doi: 10.3390/ijms 21030978

12. Huang N, Mao E-W, Hou N-N, Liu Y-P, Han F, Sun X-D. Novel insight into perirenal adipose tissue: a neglected adipose depot linking cardiovascular and chronic kidney disease. World J Diabetes. (2020) 11:11525. doi: 10.4239/wjd.v11.i4.115

13. Liu BX, Sun $W$, Kong $X Q$. Perirenal fat: a unique fat pad and potential target for cardiovascular disease. Angiology. (2019) 70:584-93. doi: $10.1177 / 0003319718799967$

14. Iacobellis G. Epicardial and pericardial fat: close, but very different. Obesity (Silver Spring, Md). (2009) 17:625; author reply 626-7. doi: 10.1038/oby.2008.622

15. Iacobellis G, Bianco AC. Epicardial adipose tissue: emerging physiological, pathophysiological and clinical features. Trends in endocrinology and metabolism: TEM. (2011) 22:450-7. doi: 10.1016/j.tem.201 1.07 .003

16. Marchington JM, Mattacks CA, Pond CM. Adipose tissue in the mammalian heart and pericardium: structure, foetal development and biochemical properties. Comp Biochem Physiol B. (1989) 94:225-32. doi: 10.1016/0305-0491(89)90337-4

17. Corradi D, Maestri R, Callegari S, Pastori P, Goldoni M, Luong TV, et al. The ventricular epicardial fat is related to the myocardial mass in normal, ischemic and hypertrophic hearts. Cardiovasc Pathol. (2004) 13:3136. doi: 10.1016/j.carpath.2004.08.005

18. Kershaw EE, Flier JS. Adipose tissue as an endocrine organ. J Clin Endocrinol Metab. (2004) 89:2548-56. doi: 10.1210/jc.2004-0395

19. Wu Y, Zhang A, Hamilton DJ, Deng T. Epicardial fat in the maintenance of cardiovascular health. Methodist DeBakey Cardiovasc J. (2017) 13:20-4. doi: 10.14797/mdcj-13-1-20

20. Sacks HS, Fain JN, Holman B, Cheema P, Chary A, Parks F, et al. Uncoupling protein-1 and related messenger ribonucleic acids in human epicardial and other adipose tissues: epicardial fat functioning as brown fat. J Clin Endocrinol Metab. (2009) 94:3611-5. doi: 10.1210/jc.2009-0571

21. Antoniades C. The interplay between adipose tissue and the cardiovascular system: is fat always bad. Eur Soc Cardiol. (2017) 32:117-23. doi: $10.1093 / \mathrm{cvr} / \mathrm{cvx} 111$

22. Djaberi R, Schuijf JD, van Werkhoven JM, Nucifora G, Jukema JW, Bax JJ. Relation of epicardial adipose tissue to coronary atherosclerosis. Am J Cardiol. (2008) 102:1602-7. doi: 10.1016/j.amjcard.2008.08.010

23. D’Marco L, Bellasi A, Raggi P. Cardiovascular biomarkers in chronic kidney disease: state of current research and clinical applicability. Dis Markers. (2015) 2015:586569. doi: $10.1155 / 2015 / 586569$
24. Wang Z, Nakayama T. Inflammation, a link between obesity and cardiovascular disease. Mediat Inflamm. (2010) 2010:535918. doi: $10.1155 / 2010 / 535918$

25. Hajer GR, van Haeften TW, Visseren FLJ. Adipose tissue dysfunction in obesity, diabetes, and vascular diseases. Eur Heart J. (2008) 29:2959-71. doi: 10.1093/eurheartj/ehn387

26. Shi Z, Chen W-W, Xiong X-Q, Han Y, Zhou Y-B, Zhang F, et al. Sympathetic activation by chemical stimulation of white adipose tissues in rats. J Appl Physiol. (2012) 112:1008-14. doi: 10.1152/japplphysiol.01164.2011

27. Tanuma $Y$, Yamamoto $M$, Ito $T$, Yokochi C. The occurrence of brown adipose tissue in perirenal fat in Japanese. Arch Histol Jpn. (1975) 38:43-70. doi: $10.1679 /$ aohc1950.38.43

28. Ochi A, Muro S, Adachi T, Akita K. Zoning inside the renal fascia: the anatomical relationship between the urinary system and perirenal fat. Int $J$ Urol. (2020) 27:625-33. doi: 10.1111/iju.14248

29. Maimaituxun G, Fukuda D, Izaki H, Hirata Y, Kanayama H, Masuzaki H, et al. Levels of adiponectin expression in peri-renal and subcutaneous adipose tissue and its determinants in human biopsied samples. Front Endocrinol. (2020) 10:897. doi: 10.3389/fendo.2019.00897

30. Lau WB, Ohashi $\mathrm{K}$, Wang $\mathrm{Y}$, Ogawa $\mathrm{H}$, Murohara T, Ma X-L, et al Role of adipokines in cardiovascular disease. Circ J. (2017) 81:920-8. doi: 10.1253/circj.CJ-17-0458

31. Karastergiou K, Fried SK. Multiple adipose depots increase cardiovascular risk via local and systemic effects. Curr Atheroscler Rep. (2013) 15:361. doi: 10.1007/s11883-013-0361-5

32. Mahabadi AA, Massaro JM, Rosito GA, Levy D, Murabito JM, Wolf PA, et al. Association of pericardial fat, intrathoracic fat, and visceral abdominal fat with cardiovascular disease burden: the Framingham Heart Study. Eur Heart J. (2008) 30:850-6. doi: 10.1093/eurheartj/ehn573

33. Sun X, Han F, Miao W, Hou N, Cao Z, Zhang G. Sonographic evaluation of para- and perirenal fat thickness is an independent predictor of early kidney damage in obese patients. Int Urol Nephrol. (2013) 45:1589-95. doi: 10.1007/s11255-013-0404-4

34. Shen FC, Cheng BC, Chen JF. Peri-renal fat thickness is positively associated with the urine albumin excretion rate in patients with type 2 diabetes. Obes Res Clin Pract. (2020) 14:345-9. doi: 10.1016/j.orcp.2020.06.006

35. Fang Y, Xu Y, Yang Y, Liu C, Zhao D, Ke J. The relationship between perirenal fat thickness and reduced glomerular filtration rate in patients with type 2 diabetes. J Diabetes Res. (2020) 2020:6076145. doi: 10.1155/2020/60 76145

36. Geraci G, Zammuto MM, Mattina A, Zanoli L, Geraci C, Granata A, et al. Para-perirenal distribution of body fat is associated with reduced glomerular filtration rate regardless of other indices of adiposity in hypertensive patients. J Clin Hypertens. (2018) 20:1438-46. doi: 10.1111/jch.13366

37. Favre G, Grangeon-Chapon C, Raffaelli C, François-Chalmin F, Iannelli A, Esnault V. Perirenal fat thickness measured with computed tomography is a reliable estimate of perirenal fat mass. PLoS ONE. (2017) 12:e0175561. doi: 10.1371/journal.pone. 0175561

38. Vogt F, Ruehm S, Hunold P, de Greiff A, Nuefer M, Barkhausen J, et al. Schnelle Ganzkörperfettmessung mittels MRT: Quantifizierung und Topografie. RöFo-Fortschritte auf dem Gebiet der Röntgenstrahlen und der bildgebenden Verfahren. (2007) 179:480-6. doi: 10.1055/s-2007-962833

39. Armellini F, Zamboni M, Rigo L, Todesco T, Bosello O, Bergamo-Andreis IA, et al. The contribution of sonography to the measurement of intra-abdominal fat. J Clin Ultrasound. (1990) 18:563-7. doi: 10.1002/jcu.1870180707

40. Kawasaki S, Aoki K, Hasegawa O, Numata K, Tanaka K, Shibata N, et al. Sonographic evaluation of visceral fat by measuring para- and perirenal fat. J Clin Ultrasound. (2008) 36:129-33. doi: 10.1002/jcu.20426

41. Lima-Martínez MM, Paoli M, Rodney M, Balladares N, Contreras M, D’Marco L, et al. Effect of sitagliptin on epicardial fat thickness in subjects with type 2 diabetes and obesity: a pilot study. Endocrine. (2016) 51:448-55. doi: 10.1007/s12020-015-0710-y

42. Erdur MF, Tonbul HZ, Ozbiner H, Ozcicek A, Ozcicek F, Akbas EM, et al The relationship between atherogenic index of plasma and epicardial adipose tissue in hemodialysis and peritoneal dialysis patients. Renal Fail. (2013) 35:1193-8. doi: 10.3109/0886022X.2013.823826

43. Turkmen K, Kayikcioglu H, Ozbek O, Solak Y, Kayrak M, Samur C, et al. The relationship between epicardial adipose tissue and malnutrition, 
inflammation, atherosclerosis/calcification syndrome in ESRD patients. Clin J Am Soc Nephrol. (2011) 6:1920-5. doi: 10.2215/CJN.00890111

44. Lamacchia O, Nicastro V, Camarchio D, Valente U, Grisorio R, Gesualdo $\mathrm{L}$, et al. Para- and perirenal fat thickness is an independent predictor of chronic kidney disease, increased renal resistance index and hyperuricaemia in type-2 diabetic patients. Nephrol Dial Transplant. (2011) 26:892-8. doi: $10.1093 /$ ndt/gfq522

45. Koo BK, Denenberg JO, Wright CM, Criqui MH, Allison MA. Associations of perirenal fat thickness with renal and systemic calcified atherosclerosis. Endocrinol Metab. (2020) 35:122-31. doi: 10.3803/EnM.2020.35.1.122

46. Ko SM, Zhang C, Chen Z, D'Marco L, Bellasi A, Stillman AE, et al. Epicardial adipose tissue volume increase in hemodialysis patients treated with sevelamer or calcium-based phosphate binders: a substudy of the Renagel in new dialysis trial. J Nephrol. (2016) 29:683-90. doi: 10.1007/s40620-016-0310-9

47. Karatas A, Canakci E, Bektas O, Bayrak T, Bayrak A, Altinbas A, et al. Relationship of epicardial fat tissue thickness with oxidant biomarkers in chronic kidney disease. Bratisl Lek Listy. (2018) 119:566-71. doi: 10.4149/BLL 2018_102

48. Ayan H, Akilli R, Kaya B, Paydas S, Kara E, Cureoglu A. Relationship between SCUBE1 levels and echocardiography and electrocardiography findings and epicardial adipose tissue/carotid intima-media thickness in patients receiving renal replacement therapy. Exp Clin Transpl. (2019) 17(Suppl. 1):181-7. doi: 10.6002/ect.MESOT2018.P58

49. Cano Megías M, Guisado Vasco P, Bouarich H, Aguilera IL, de Arriba-de la Fuente G, Rodríguez-Puyol D. Tejido graso epicárdico, calcificación arterial coronaria y mortalidad en pacientes con enfermedad renal crónica avanzada y hemodiálisis. Nefrología. (2021) 41:172-81. doi: 10.1016/j.nefro.2020.09.005

50. Song G, Qiao W, Liu K, Yu X. Epicardial adipose tissue in patients with chronic kidney disease: a meta-analysis study and trial sequential analysis. Int Urol Nephrol. (2020) 52:2345-55. doi: 10.1007/s11255-020-02575-y

51. de Pergola G, Campobasso N, Nardecchia A, Triggiani V, Caccavo D, Gesualdo L, et al. Para- and perirenal ultrasonographic fat thickness is associated with 24-hours mean diastolic blood pressure levels in overweight and obese subjects. BMC Cardiovasc Disord. (2015) 15:1-7. doi: 10.1186/s12872-015-0101-6

52. Bassols J, Martínez-Calcerrada J-M, Prats-Puig A, Carreras-Badosa G, Xargay-Torrent S, Lizarraga-Mollinedo E, et al. Perirenal fat is related to carotid intima-media thickness in children. Int J Obes. (2018) 42:641-7. doi: 10.1038/ijo.2017.236

53. Jespersen NZ, Feizi A, Andersen ES, Heywood S, Hattel HB, Daugaard S, et al. Heterogeneity in the perirenal region of humans suggests presence of dormant brown adipose tissue that contains brown fat precursor cells. Mol Metab. (2019) 24:30-43. doi: 10.1016/j.molmet.2019.03.005

54. Gaborit B, Venteclef N, Ancel P, Pelloux V, Gariboldi V, Leprince P, et al. Human epicardial adipose tissue has a specific transcriptomic signature depending on its anatomical peri-atrial, peri-ventricular, or peri-coronary location. Cardiovasc Res. (2015) 108:62-73. doi: 10.1093/cvr/cvv208

55. Tanida M, Iwashita S, Ootsuka Y, Terui N, Suzuki M. Leptin injection into white adipose tissue elevates renal sympathetic nerve activity dosedependently through the afferent nerves pathway in rats. Neurosci Lett. (2000) 293:107-10. doi: 10.1016/S0304-3940(00)01490-7

56. Schleinitz D, Krause K, Wohland T, Gebhardt C, Linder N, Stumvoll $\mathrm{M}$, et al. Identification of distinct transcriptome signatures of human adipose tissue from fifteen depots. Eur J Hum Genet. (2020) 28:1714-25. doi: 10.1038/s41431-020-0681-1

57. Marthi A, Donovan K, Haynes R, Wheeler DC, Baigent C, Rooney $\mathrm{CM}$, et al. Fibroblast growth factor- 23 and risks of cardiovascular and noncardiovascular diseases: a meta-analysis. J Am Soc Nephrol. (2018) 29:2015-27. doi: 10.1681/ASN.2017121334

58. Tsuji K, Maeda T, Kawane T, Matsunuma A, Horiuchi N. Leptin stimulates fibroblast growth factor 23 expression in bone and suppresses renal 1alpha,25dihydroxyvitamin D3 synthesis in leptin-deficient mice. J Bone Miner Res. (2010) 25:1711-23. doi: 10.1002/jbmr.65
59. Spoto B, Pizzini P, Tripepi G, Mallamaci F, Zoccali C. Circulating adiponectin modifies the FGF23 response to vitamin D receptor activation: a post hoc analysis of a double-blind, randomized clinical trial. Nephrol Dial Transplant. (2018) 33:1764-9. doi: 10.1093/ndt/gfx344

60. Mirza MAI, Alsiö J, Hammarstedt A, Erben RG, Michaëlsson K, Tivesten A, et al. Circulating fibroblast growth factor-23 is associated with fat mass and dyslipidemia in two independent cohorts of elderly individuals. Arterioscler Thromb Vasc Biol. (2011) 31:219-27. doi: 10.1161/ATVBAHA.110.214619

61. Kerr JD, Holden RM, Morton AR, Nolan RL, Hopman WM, Pruss CM, et al. Associations of epicardial fat with coronary calcification, insulin resistance, inflammation, and fibroblast growth factor-23 in stage 3-5 chronic kidney disease. BMC Nephrology. (2013) 14:26. doi: 10.1186/1471-2369-14-26

62. Nakazato R, Rajani R, Cheng VY, Shmilovich H, Nakanishi R, Otaki Y, et al. Weight change modulates epicardial fat burden: a 4-year serial study with non-contrast computed tomography. Atherosclerosis. (2012) 220:139-44. doi: 10.1016/j.atherosclerosis.2011.10.014

63. Parisi V, Petraglia L, D'Esposito V, Cabaro S, Rengo G, Caruso A, et al. Statin therapy modulates thickness and inflammatory profile of human epicardial adipose tissue. Int J Cardiol. (2019) 274:326-30. doi: 10.1016/j.ijcard.2018.06.106

64. Alexopoulos N, Melek BH, Arepalli CD, Hartlage G-R, Chen Z, Kim S, et al. Effect of intensive versus moderate lipid-lowering therapy on epicardial adipose tissue in hyperlipidemic post-menopausal women: a substudy of the BELLES trial (beyond endorsed lipid lowering with EBT scanning). J Am Coll Cardiol. (2013) 61:1956-61. doi: 10.1016/j.jacc.2012.12.051

65. Subbotin VM. Neovascularization of coronary tunica intima (DIT) is the cause of coronary atherosclerosis. Lipoproteins invade coronary intima via neovascularization from adventitial vasa vasorum, but not from the arterial lumen: a hypothesis. Theor Biol Med Model. (2012) 9:11. doi: $10.1186 / 1742-4682-9-11$

66. Couselo-Seijas M, Agra-Bermejo RM, Fernández AL, Martínez-Cereijo JM, Sierra J, Soto-Pérez M, et al. High released lactate by epicardial fat from coronary artery disease patients is reduced by dapagliflozin treatment. Atherosclerosis. (2020) 292:62-9. doi: 10.1016/j.atherosclerosis.2019.11.016

67. Zhao Y, Gao P, Sun F, Li Q, Chen J, Yu H, et al. Sodium intake regulates glucose homeostasis through the PPAR $\delta /$ adiponectin-mediated SGLT2 pathway. Cell Metab. (2016) 23:699-711. doi: 10.1016/j.cmet.2016.02.019

68. Morano S, Romagnoli E, Filardi T, Nieddu L, Mandosi E, Fallarino M, et al. Short-term effects of glucagon-like peptide 1 (GLP-1) receptor agonists on fat distribution in patients with type 2 diabetes mellitus: an ultrasonography study. Acta Diabetol. (2015) 52:727-32. doi: 10.1007/s00592-014-0710-z

69. Sacks HS, Fain JN, Cheema P, Bahouth SW, Garrett E, Wolf RY, et al. Inflammatory genes in epicardial fat contiguous with coronary atherosclerosis in the metabolic syndrome and type 2 diabetes: changes associated with pioglitazone. Diabetes Care. (2011) 34:730-3. doi: 10.2337/dc10-2083

70. Rodríguez-Osorio L, Pazmiño Zambrano D, Gracia-Iguacel C, Rojas-Rivera J, Ortiz A, Egido J, et al. Uso del sevelamer en la enfermedad renal crónica: más allá del control del fósforo TT-Using sevelamer in chronic kidney disease: beyond phosphorus control. Nefrología (Madrid). (2015) 35:207-17. doi: $10.1016 /$ j.nefro.2015.05.022

Conflict of Interest: The authors declare that the research was conducted in the absence of any commercial or financial relationships that could be construed as a potential conflict of interest.

Copyright (๑) 2021 D’Marco, Puchades, Panizo, Romero-Parra, Gandía, GiménezCivera, Pérez-Bernat, Gonzalez-Rico and Gorriz. This is an open-access article distributed under the terms of the Creative Commons Attribution License (CC BY). The use, distribution or reproduction in other forums is permitted, provided the original author(s) and the copyright owner(s) are credited and that the original publication in this journal is cited, in accordance with accepted academic practice. No use, distribution or reproduction is permitted which does not comply with these terms. 